\title{
A Prospective Birth Cohort Study on Maternal Cholesterol Levels and Offspring Attention Deficit Hyperactivity Disorder: New Insight on Sex Differences
}

Yuelong Ji ${ }^{1}$, Anne W. Riley ${ }^{1}$, Li-Ching Lee ${ }^{2,3}{ }^{\text {, Heather Volk }}{ }^{3}$, Xiumei Hong ${ }^{1}$, Guoying Wang ${ }^{1}$, Rayris Angomas ${ }^{4}$, Tom Stivers ${ }^{4}$, Anastacia Wahl ${ }^{4}$, Hongkai Ji ${ }^{5}$, Tami R. Bartell ${ }^{6}$, Irina Burd ${ }^{7}$, David Paige ${ }^{1}$, Margaret D. Fallin ${ }^{2,3}$, Barry Zuckerman ${ }^{4}$ and Xiaobin Wang ${ }^{1,8, *}$

1 Center on the Early Life Origins of Disease, Department of Population, Family and Reproductive Health, Johns Hopkins University Bloomberg School of Public Health, 615 N Wolfe St, Baltimore, MD 21205, USA; yji7@jhu.edu (Y.J.); ariley1@jhu.edu (A.W.R.); xhong3@jhu.edu (X.H.); gwang24@jhu.edu (G.W.);

dpaige@jhu.edu (D.P.)

2 Department of Epidemiology, Johns Hopkins University Bloomberg School of Public Health, 615 N Wolfe St, Baltimore, MD 21205, USA; llee38@jhu.edu (L-C.L.); dfallin@jhu.edu (M.D.F.)

3 Wendy Klag Center for Autism and Developmental Disabilities \& Department of Mental Health, 615 N Wolfe St, Baltimore, MD 21205, USA; hvolk1@jhu.edu

4 Department of Pediatrics, Boston University School of Medicine and Boston Medical Center, 1 Boston Medical Center Place, Boston, MA 02118, USA; Rayris.Angomas@bmc.org (R.A.);

Tom.Stivers@bmc.org (T.S.); awahl@bu.edu (A.W.); barryzuckerman1@gmail.com (B.Z.)

5 Department of Biostatistics, Johns Hopkins University Bloomberg School of Public Health, 615 N Wolfe St, Baltimore, MD 21205, USA; hji@jhu.edu

6 Stanley Manne Children's Research Institute, Mary Ann \& J. Milburn Smith Child Health Research, Outreach and Advocacy Center, Ann \& Robert H. Lurie Children's Hospital of Chicago,

225 E Chicago Avenue, Chicago, IL 60611, USA; TBartell@luriechildrens.org

7 Integrated Research Center for Fetal Medicine, Department of Gynecology and Obstetrics, Johns Hopkins University School of Medicine, 1800 Orleans St, Baltimore, MD 21287, USA; iburd@jhmi.edu

8 Division of General Pediatrics \& Adolescent Medicine, Department of Pediatrics, Johns Hopkins University School of Medicine, 1800 Orleans St, Baltimore, MD 21287, USA

* Correspondence: xwang82@jhu.edu; Tel.: +1-410-955-5824; Fax: 410-502-5831

Received: 4 December 2017; Accepted: 20 December 2017; Published: 23 December 2017

Abstract: Growing evidence suggests that maternal cholesterol levels are important in the offspring's brain growth and development. Previous studies on cholesterols and brain functions were mostly in adults. We sought to examine the prospective association between maternal cholesterol levels and the risk of attention deficit hyperactivity disorder (ADHD) in the offspring. We analyzed data from the Boston Birth Cohort, enrolled at birth and followed from birth up to age 15 years. The final analyses included 1479 mother-infant pairs: 303 children with ADHD, and 1176 neurotypical children without clinician-diagnosed neurodevelopmental disorders. The median age of the first diagnosis of ADHD was seven years. The multiple logistic regression results showed that a low maternal high-density lipoprotein level $(\leq 60 \mathrm{mg} / \mathrm{dL})$ was associated with an increased risk of ADHD, compared to a higher maternal high-density lipoprotein level, after adjusting for pertinent covariables. A "J" shaped relationship was observed between triglycerides and ADHD risk. The associations with ADHD for maternal high-density lipoprotein and triglycerides were more pronounced among boys. The findings based on this predominantly urban low-income minority birth cohort raise a new mechanistic perspective for understanding the origins of ADHD and the gender differences and future targets in the prevention of ADHD.

Keywords: high-density lipoprotein; triglyceride; sex difference; ADHD 


\section{Introduction}

In the US, attention deficit hyperactivity disorder (ADHD) is one of the most common neurodevelopmental disorders in children; its prevalence has risen from $7.0 \%$ to $10.2 \%$ among children aged 4-17 years during the past two decades [1], representing a nearly 5\% increase each year since 2003 [2]. ADHD is characterized by inattention, hyperactivity, or impulsiveness [3-5], and is three times more common among males than females [6]. Approximately $66 \%$ to $85 \%$ of children diagnosed with ADHD will carry their disorder into adolescence and adulthood [7,8]. A 2007 estimation of the annual cost of ADHD in the US, including the cost of related health care utilization, medication, education, crime, and unemployment, was $\$ 14,500$ per child ( $\$ 42.5$ billion in total) [9]. While ADHD medications have shown to be effective in controlling ADHD symptoms, they neither preclude the rising incidence of ADHD nor cure ADHD, not to mention that they are also the causes for additional costs and potential side effects [2]. Given its high prevalence and continuously rising trend, the impact of ADHD on individual families and society is expected to increase dramatically [7,9,10].

At present, our knowledge regarding the biological mechanisms of ADHD development and effective ways to prevent ADHD is insufficient. While research has identified several potential etiological mechanisms, such as gene variants, brain structural abnormalities, and neurotransmitter deficiency and dysregulation [11,12], much more work is needed to fully understand the early life determinants of ADHD and significant sex differences in ADHD risk. There is an urgent need to identify modifiable early life risk factors for ADHD, which are essential to the primary prevention efforts. Well-recognized environmental risk factors for ADHD include parent-related factors [13-25], low birthweight and preterm birth [26], exposure to organophosphates [27], polychlorinated biphenyls [28,29], and lead [28,30-32]. Besides those factors, multiple recent studies indicate that maternal metabolic profiles may also influence offspring's neurodevelopment. For example, findings in the Boston Birth Cohort showed a strong association between maternal obesity and diabetes and increased risk of autism in childhood [33]. A large longitudinal study, using prospective pregnancy cohorts from the Nordic Network, showed that both overweight moms and moms with excessive weight gain during gestation had an over two-fold higher risk of having ADHD children [34]. However, no study has investigated the role of maternal dyslipidemia (a condition often associated with obesity or metabolic syndrome) in offspring's ADHD development.

Maternal cholesterol levels are biologically plausible to influence neurodevelopment in the offspring [33-40]. Besides cholesterol's key functions, such as hormone synthesis, fat-soluble vitamin digestion and absorption, cell membrane stabilization, and inter-cellular communication, it is essential for normal brain development, especially during in-utero and early childhood [35-37]. Nearly 70\% to $80 \%$ of brain cholesterol is present in myelin [41]. While fetal cholesterol can be synthesized endogenously [38], the placenta also delivers cholesterol from maternal circulation to the fetus through multiple cholesterol-carrying lipoproteins, such as low-density lipoproteins (LDL), high-density lipoproteins (HDL) and very low-density lipoproteins (VLDL) [39,40]. It was estimated that up to 20\% of fetal cholesterol in the first trimester is derived from maternal cholesterol via the placenta [38].

During normal pregnancy in humans, maternal blood cholesterol levels increase with gestational age to meet the increasing demands of fetal growth and development, especially with regards to the fetal brain [42-44]. Conceivably, a dysregulation in the amount and the type of cholesterol during critical developmental windows could lead to suboptimal neurodevelopment, and subsequently, ADHD symptoms in childhood. However, this possibility remains to be explored. To our knowledge, existing cholesterol studies in humans have mainly focused on mental health outcomes in adults, in which HDL levels have been found to be associated with multiple cognitive impairments and neurodegenerative diseases [45-47]. In particular, there is a lack of prospective birth cohort study to investigate the inter-generational impact of cholesterol on ADHD.

To fill in the aforementioned knowledge gaps, in this study, we sought to examine the prospective association between maternal cholesterol levels $24-72 \mathrm{~h}$ after delivery and the development of ADHD in the offspring using a longitudinal birth cohort design. Findings from such a study have important 
clinical and public health implications. The current clinical guidelines for optimal cholesterol levels have been set for non-pregnant women based on cardio-metabolic outcomes, aiming to control cholesterol levels. However, the requirements for optimal nutrition, including cholesterols, are higher during pregnancy due to the increasing demands of the uterus, placenta, and fetal growth. Furthermore, no guidelines for cholesterol levels have been established for pregnant women in the context of fetal brain growth and long-term neurodevelopmental outcomes.

\section{Materials and Methods}

\subsection{Study Sample}

The Boston Birth Cohort (BBC) has successfully recruited mother-infant pairs at birth; the participation rate has been $>90 \%$ among eligible mothers approached by the research staff. Details of the recruitment of the BBC were published previously [48,49]. Eligible mothers were those who delivered a single live birth at Boston Medical Center (BMC). Pregnancies resulting from in vitro fertilization, multiple-gestation pregnancies, deliveries induced by maternal trauma, or newborns with substantial congenital disabilities were not eligible for enrollment. The Institutional Review Board (IRB) of the Boston University Medical Center and Johns Hopkins Bloomberg School of Public Health approved the BBC study. Informed consent was obtained from each participant under the IRB approved protocol (IRB No. 00003966).

Of enrolled mother-infant pairs at birth in the BBC, 3098 who continued to receive pediatric primary care at BMC were enrolled in a postnatal follow-up study [33,48,50]. Our study sample excluded participants who had missing maternal cholesterol measurements and key covariates. We further excluded children with physician-diagnosed neurodevelopmental disorders other than ADHD (Table S1). Our final analyses consisted of 1479 mother-infant pairs, including 303 children with ADHD and 1176 neurotypical children (Figure 1). The maternal and child characteristics for participants excluded and included are compared in Table S2.

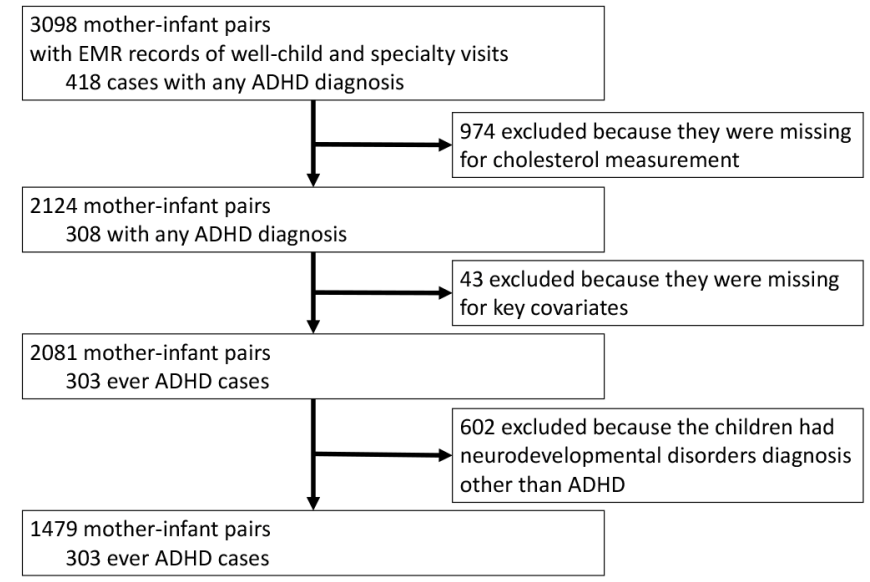

Figure 1. Flowchart of the sample included in the analyses.

\subsection{Data Collection Procedures and Measures of Key Variables}

Mother-infant pairs were enrolled 24 to $72 \mathrm{~h}$ after birth. After obtaining informed consent, face-to-face interviews using a standardized questionnaire were conducted to collect mothers' reports on family socio-demographics, substance use, and other prenatal exposure information. The maternal and newborn medical records were extracted using a standardized abstraction form. Since 2003, electronic medical records (EMRs) have become part of routine clinical data collection for the BBC, including both well-child and specialty medical visits at BMC. For each primary care visit, the EMRs 
contain the primary and secondary diagnoses from the International Classification of Diseases, Ninth Revision (ICD-9) (before 1 October 2015) and ICD-10 (after 1 October 2015).

Maternal serum total cholesterol (TC), triglycerides (TG), and high-density lipoprotein (HDL) levels were measured using nonfasting blood samples obtained between 24 to $72 \mathrm{~h}$ after delivery. Serum low-density lipoprotein (LDL) levels were calculated using the Friedwald equation. The detailed measurement and calculation methods are described in our previous publication [51]. Of note, nonfasting samples primarily impact TC and TG levels, which may be higher than in a fasting state.

The "ADHD group" was defined as having any of the following clinician-diagnosed ICD-9 codes: [314.0 (Attention deficit disorder of childhood), 314.00 (Attention deficit disorder without mention of hyperactivity), 314.01 (Attention deficit disorder with hyperactivity), 314.1 (Hyperkinesis with developmental delay), 314.2 (Hyperkinetic conduct disorder), 314.8 (Other specified manifestations of hyperkinetic syndrome), and 314.9 (Unspecified hyperkinetic syndrome)], or any of the following ICD-10 codes: F90.0 (ADHD, predominantly inattentive type), F90.1 (ADHD, predominantly hyperactive type), F90.2 (ADHD, combined type), F90.8 (ADHD, other type), and F90.9 (ADHD, unspecified type), as documented in the child's EMRs.

The "neurotypical (NT) group" was defined as not having any clinician diagnosis of autism spectrum disorder, ADHD, conduct disorders, developmental delays, intellectual disabilities, failure to thrive, or congenital anomalies. This definition was established by clinical experts and has been applied by multiple published papers [52,53]. The ICD-9 and ICD-10 codes for the diagnoses of these developmental disorders are listed in Table S1.

\subsection{Statistical Analysis}

The characteristics of the study sample between the "ADHD" and the "NT" groups were examined by t-test for continuous variables and $\chi^{2}$ test for categorical variables. TC, HDL, LDL, and TG were further analyzed as categorical variables based on clinically-established cut-off points $[54,55]$, in addition to quartiles and the linear trend test. The clinical cut-off point for low HDL for women is $<50 \mathrm{mg} / \mathrm{dL}$ [55]. The clinical cut-off point for non-fasting high TG is $\geq 200 \mathrm{mg} / \mathrm{dL}$ [54]. The quartile cut-off points were: TC ( $<176 \mathrm{mg} / \mathrm{dL}, 176-214 \mathrm{mg} / \mathrm{dL}, 215-254 \mathrm{mg} / \mathrm{dL},>254 \mathrm{mg} / \mathrm{dL})$, TG (<135 mg/dL, 135-176 mg/dL, 177-232 mg/dL, $>232 \mathrm{mg} / \mathrm{dL})$, HDL ( $<50 \mathrm{mg} / \mathrm{dL}, 50-60 \mathrm{mg} / \mathrm{dL}$, 61-73 mg/dL, >73 mg/dL), and LDL ( $<96 \mathrm{mg} / \mathrm{dL}, 96-121 \mathrm{mg} / \mathrm{dL}, 122-150 \mathrm{mg} / \mathrm{dL},>150 \mathrm{mg} / \mathrm{dL}$ ). Next, we conducted multiple logistic regression (MLR) to examine the association between TC, HDL, LDL, and TG and the risk of ADHD diagnosis, both categorically and continuously, adjusting for maternal age at delivery, maternal race/ethnicity, maternal education, smoking during pregnancy, intrauterine infection, parity, child's sex, mode of delivery, preterm birth, and birthweight. The effect of the interaction between child's sex and each type of lipid or lipoprotein level on the risk of ADHD was tested using MLR and adjusted for the same set of covariates. Similarly, the joint effect of the child's sex with each type of lipid or lipoprotein on the risk of ADHD was tested using MLR and adjusted for the same set of covariates except for child's sex. In the sensitivity analyses, stratified analysis by each major covariate was conducted for the association between maternal HDL and ADHD. Furthermore, we repeated the above analyses within two subsets. One subset only included specialist-diagnosed ADHD as cases, while the other subset only included the ADHD cases whose age of last ADHD diagnosis was six years or older. We also performed additional analyses for the association between maternal cholesterol profiles and the risk of other neurodevelopmental disorders other than ADHD. All analyses were performed using STATA ${ }^{\circledR}$ version 14.0 software (Stata Corporation, College Station, TX, USA).

\section{Results}

There were 303 children with a clinician diagnosis of ADHD. Of these, 214 were diagnosed by a developmental specialist and 89 by a general pediatrician. The median age at the first ADHD diagnosis was seven years. Table 1 presents the bivariate comparisons of maternal and child characteristics 
between the "ADHD" and "NT" groups. The mothers of children with an ADHD diagnosis were more likely to have below college degree education, ever smoke before or during pregnancy, $\mathrm{C}$-section delivery, lower TC, lower HDL, and lower LDL, compared with the neurotypical group. The children with any ADHD diagnosis were more likely to be older, male, born prematurely, and have had low birthweight, compared with the neurotypical group. The comparison results of major characteristics between excluded and included samples indicate that the included sample had less exposure to multiple risk factors, such as smoking during pregnancy, C-section delivery, lower gestational age, and lower birthweight (Table S2).

Table 1. Maternal and child characteristics for children with any attention deficit hyperactivity disorder (ADHD) diagnosis and neurotypical children (NT).

\begin{tabular}{|c|c|c|c|c|}
\hline Variable & Total, No. (\%) & NT, No. (\%) & ADHD, No. (\%) & $p$-Value $\ddagger$ \\
\hline Total & $1479(100)$ & $1176(79.5)$ & $303(20.5)$ & \\
\hline Maternal Age & & & & 0.317 \\
\hline$<20$ & $148(10.0)$ & $111(9.4)$ & $37(12.2)$ & \\
\hline $20-34$ & $1080(73.0)$ & $867(73.8)$ & $213(70.3)$ & \\
\hline$\geq 35$ & $251(17.0)$ & $198(16.8)$ & $53(17.5)$ & \\
\hline Education level & & & & 0.022 \\
\hline Below college degree & $1278(86.4)$ & $1004(85.4)$ & $274(90.4)$ & \\
\hline College degree or above & $201(13.6)$ & $172(14.6)$ & $29(9.6)$ & \\
\hline Race-ethnicity & & & & 0.230 \\
\hline Black & $968(65.5)$ & $759(64.5)$ & $209(69.0)$ & \\
\hline White & $74(5.0)$ & $56(4.8)$ & $18(5.9)$ & \\
\hline Hispanic & $357(24.1)$ & $293(24.9)$ & $64(21.1)$ & \\
\hline Others & $80(5.4)$ & $68(5.8)$ & $12(4.0)$ & \\
\hline Parity & & & & 0.901 \\
\hline Nulliparous & $625(42.3)$ & $496(42.2)$ & $129(42.6)$ & \\
\hline Multiparous & $854(57.7)$ & $680(57.8)$ & $174(57.4)$ & \\
\hline Smoking during pregnancy & & & & $<0.001$ \\
\hline Never & $1229(83.1)$ & $998(84.9)$ & $231(76.2)$ & \\
\hline Quitter & $111(7.5)$ & $72(6.1)$ & $39(12.9)$ & \\
\hline Continuous & $139(9.4)$ & $106(9.0)$ & $33(10.9)$ & \\
\hline Intrauterine infection & & & & 0.060 \\
\hline No & $1292(87.4)$ & $1037(88.2)$ & $255(84.2)$ & \\
\hline Yes & $187(12.6)$ & $139(11.8)$ & $48(15.8)$ & \\
\hline Child's sex & & & & $<0.001$ \\
\hline Female & $749(50.6)$ & $664(56.5)$ & $85(28.1)$ & \\
\hline Male & $730(49.4)$ & $512(43.5)$ & $218(71.9)$ & \\
\hline Delivery type & & & & 0.008 \\
\hline C-section & $500(33.8)$ & $378(32.1)$ & $122(40.3)$ & \\
\hline Vaginal & $979(66.2)$ & $798(67.9)$ & $181(59.7)$ & \\
\hline Season of child's birth & & & & 0.797 \\
\hline Jan to March & $333(22.5)$ & $264(22.5)$ & $69(22.8)$ & \\
\hline April to June & $350(23.7)$ & $279(23.7)$ & $71(23.4)$ & \\
\hline July to September & $402(27.2)$ & $314(26.7)$ & $88(29.0)$ & \\
\hline October to December & $394(26.6)$ & $319(27.1)$ & $75(24.8)$ & \\
\hline Preterm birth (<37 weeks) & & & & 0.005 \\
\hline No & $1125(76.1)$ & $913(77.6)$ & $212(70.0)$ & \\
\hline Yes & $354(23.9)$ & $263(22.4)$ & $91(30.0)$ & \\
\hline Low birthweight $(<2500 \mathrm{~g})$ & & & & 0.028 \\
\hline No & $1148(77.6)$ & $927(78.8)$ & $221(72.9)$ & \\
\hline Yes & $331(22.4)$ & $249(21.2)$ & $82(27.1)$ & \\
\hline
\end{tabular}


Table 1. Cont.

\begin{tabular}{|c|c|c|c|c|}
\hline Variable & Total, No. (\%) & NT, No. (\%) & ADHD, No. (\%) & $p$-Value $\ddagger$ \\
\hline Gestational age, week & & & & $<0.001$ \\
\hline Mean (SD) & $38.1(3.1)$ & $38.2(2.9)$ & $37.5(3.8)$ & \\
\hline Birthweight, $\mathrm{g}$ & & & & 0.007 \\
\hline Mean (SD) & $2996.7(754.0)$ & $3023.3(716.4)$ & $2893.5(878.9)$ & \\
\hline Maternal TC, mg/dL & & & & 0.018 \\
\hline Mean (SD) & $219.6(60.9)$ & $221.5(61.3)$ & $212.2(58.9)$ & \\
\hline Maternal TG, mg/dL & & & & 0.838 \\
\hline Mean (SD) & $191.9(80.6)$ & $192.2(80.1)$ & $191.1(83.0)$ & \\
\hline Maternal HDL, mg/dL & & & & $<0.001$ \\
\hline Mean (SD) & $62.0(17.6)$ & $62.8(17.9)$ & $58.8(15.8)$ & \\
\hline Maternal LDL, mg/dL & & & & 0.011 \\
\hline Mean (SD) & $126.6(41.8)$ & $128.0(42.1)$ & $121.2(39.9)$ & \\
\hline Age of child, years & & & & $<0.001$ \\
\hline Mean (SD) & $10.6(3.3)$ & $10.3(3.3)$ & $11.7(3.2)$ & \\
\hline
\end{tabular}

Table 2 shows the MLR results for the effects of TC, HDL, LDL, and TG on the risk of any ADHD diagnosis, after adjusting for pertinent covariates. $\mathrm{HDL}<50 \mathrm{mg} / \mathrm{dL}$, indicating a moderate risk of heart disease, was not associated with an increased risk of ADHD diagnosis (Odds Ratio $(\mathrm{OR})=1.30$, $95 \%$ Confidence Interval (CI) $(0.96,1.74))$. When HDL levels were analyzed as quartiles, mothers with first or second quartile HDL levels showed similarly increased odds of having a child with any ADHD diagnosis compared to those with fourth quartile HDL levels (Q2 vs. Q4: OR $=1.42,95 \% \mathrm{CI}(0.96,2.09)$; Q1 vs. Q4: $\mathrm{OR}=1.54,95 \% \mathrm{CI}(1.04,2.28))$. Mothers with $\leq$ median HDL levels had a $39 \%$ increased odds of having a child with any ADHD diagnosis as compared to mothers with >median HDL levels $(\mathrm{OR}=1.39,95 \% \mathrm{CI}(1.06,1.82))$. When HDL was analyzed as a continuous variable, the average odds of having a child with any ADHD diagnosis dropped $19 \%$ for every $20 \mathrm{mg} / \mathrm{dL}$ increase in maternal HDL levels $(\mathrm{OR}=0.81,95 \% \mathrm{CI}(0.69,0.95))$.

Table 2. The association between maternal cholesterol and the risk of ADHD in offspring.

\begin{tabular}{|c|c|c|c|c|c|c|c|c|c|c|c|}
\hline \multicolumn{2}{|c|}{ Maternal Cholesterols } & \multirow{2}{*}{$\begin{array}{c}\text { ADHD, } \\
\text { No. (\%) } \\
213(19.2)\end{array}$} & \multirow{2}{*}{$\begin{array}{c}\begin{array}{c}\text { NT, No. } \\
(\%)\end{array} \\
898(80.8)\end{array}$} & \multirow{2}{*}{$\begin{array}{c}\begin{array}{c}\text { Crude } \\
\text { OR }\end{array} \\
1.00\end{array}$} & \multicolumn{2}{|c|}{$95 \%$ CI } & \multirow[t]{2}{*}{$p$-Value } & \multirow{2}{*}{$\begin{array}{c}\begin{array}{c}\text { Adjusted } \\
\text { OR }\end{array} \\
1.00\end{array}$} & \multicolumn{2}{|c|}{$95 \%$ CI } & \multirow[t]{2}{*}{$p$-Value } \\
\hline HDL clinical & $\geq 50 \mathrm{mg} / \mathrm{dL}$ & & & & & & & & & & \\
\hline cut-off & $<50 \mathrm{mg} / \mathrm{dL}$ & $90(24.5)$ & $278(75.5)$ & 1.36 & 1.03 & 1.81 & 0.030 & 1.30 & 0.96 & 1.74 & 0.085 \\
\hline \multirow{3}{*}{ HDL quartiles } & $\mathrm{Q} 4$ (>73 mg/dL) & $55(15.3)$ & $304(84.7)$ & 1.00 & & & & 1.00 & & & \\
\hline & Q3 (61-73 mg/dL) & $67(18.1)$ & $304(81.9)$ & 1.22 & 0.82 & 1.80 & 0.322 & 1.11 & 0.74 & 1.67 & 0.606 \\
\hline & Q2 (50-60 mg/dL) & $91(23.9)$ & $290(76.1)$ & 1.73 & 1.20 & 2.51 & 0.004 & 1.42 & 0.96 & 2.09 & 0.079 \\
\hline \multirow[t]{2}{*}{ HDL binary } & $\begin{array}{l}\text { >median } \\
(60 \mathrm{mg} / \mathrm{dL})\end{array}$ & $122(16.7)$ & $608(83.3)$ & 1.00 & & & & 1.00 & & & \\
\hline & $\begin{array}{l}\leq \text { median } \\
(60 \mathrm{mg} / \mathrm{dL})\end{array}$ & $181(24.2)$ & $568(75.8)$ & 1.59 & 1.23 & 2.05 & $<0.001$ & 1.39 & 1.06 & 1.82 & 0.016 \\
\hline \multicolumn{2}{|c|}{$\begin{array}{l}\text { HDL linear trend } \\
\text { (every } 20 \mathrm{mg} / \mathrm{dL} \text { increase) }\end{array}$} & $303(20.5)$ & $1176(79.5)$ & 0.76 & 0.65 & 0.88 & $<0.001$ & 0.81 & 0.69 & 0.95 & 0.011 \\
\hline \multirow{3}{*}{ TG quartiles } & Q2 (135-176 mg/dL) & $58(16.3)$ & $297(83.7)$ & 0.62 & 0.43 & 0.90 & 0.012 & 0.63 & 0.43 & 0.93 & 0.020 \\
\hline & Q3 (177-232 mg/dL) & $76(20.7)$ & $291(79.3)$ & 0.83 & 0.59 & 1.18 & 0.300 & 0.88 & 0.61 & 1.27 & 0.495 \\
\hline & $\mathrm{Q} 4$ (>232 mg/dL) & $79(20.8)$ & $301(79.2)$ & 0.84 & 0.59 & 1.18 & 0.309 & 0.98 & 0.66 & 1.44 & 0.909 \\
\hline
\end{tabular}


Table 2. Cont.

\begin{tabular}{|c|c|c|c|c|c|c|c|c|c|c|c|}
\hline \multicolumn{2}{|c|}{ Maternal Cholesterols } & \multirow{2}{*}{$\begin{array}{l}\text { ADHD, } \\
\text { No. (\%) } \\
58(16.3)\end{array}$} & \multirow{2}{*}{$\begin{array}{c}\begin{array}{c}\text { NT, No. } \\
(\%)\end{array} \\
297(83.7)\end{array}$} & \multirow{2}{*}{$\begin{array}{c}\begin{array}{c}\text { Crude } \\
\text { OR }\end{array} \\
1.00\end{array}$} & \multicolumn{2}{|c|}{$95 \% \mathrm{CI}$} & \multirow[t]{2}{*}{$p$-Value } & \multirow{2}{*}{$\begin{array}{c}\begin{array}{c}\text { Adjusted } \\
\text { OR }\end{array} \\
1.00\end{array}$} & \multicolumn{2}{|c|}{$95 \%$ CI } & \multirow[t]{2}{*}{$p$-Value } \\
\hline TC hin & Q2 & & & & & & & & & & \\
\hline 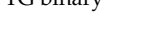 & Q1, Q3, Q4 & $245(21.8)$ & $879(78.2)$ & 1.43 & 1.04 & 1.96 & 0.027 & 1.51 & 1.08 & 2.10 & 0.015 \\
\hline $\begin{array}{l}\text { TG linear trend } \\
\text { (every } 20 \mathrm{mg} / \mathrm{c}\end{array}$ & increase) & $303(20.5)$ & $1176(79.5)$ & 1.00 & 0.97 & 1.03 & 0.838 & 1.02 & 0.98 & 1.06 & 0.348 \\
\hline \multirow{4}{*}{ LDL quartiles } & Q1 (<96 mg/dL) & $87(23.6)$ & $282(76.4)$ & 1.00 & & & & 1.00 & & & \\
\hline & Q2 (96-121 mg/dL) & $80(21.8)$ & 287 (78.2) & 0.90 & 0.64 & 1.28 & 0.565 & 0.91 & 0.63 & 1.31 & 0.603 \\
\hline & Q3 (122-150 mg/dL) & $67(18.2)$ & $301(81.8)$ & 0.72 & 0.50 & 1.03 & 0.074 & 0.82 & 0.57 & 1.20 & 0.316 \\
\hline & $\mathrm{Q} 4$ (>150 mg/dL) & $69(18.4)$ & $306(81.6)$ & 0.73 & 0.51 & 1.04 & 0.083 & 0.76 & 0.52 & 1.11 & 0.153 \\
\hline \multicolumn{2}{|c|}{$\begin{array}{l}\text { LDL linear trend } \\
\text { (every } 20 \mathrm{mg} / \mathrm{dL} \text { increase) }\end{array}$} & $303(20.5)$ & $1176(79.5)$ & 0.92 & 0.87 & 0.98 & 0.011 & 0.93 & 0.87 & 0.99 & 0.033 \\
\hline \multirow{4}{*}{ TC quartiles } & Q1 (<176 mg/dL) & $92(24.6)$ & $282(75.4)$ & 1.00 & & & & 1.00 & & & \\
\hline & Q2 (176-214 mg/dL) & $73(20.3)$ & 287 (79.7) & 0.78 & 0.55 & 1.10 & 0.161 & 0.82 & 0.57 & 1.18 & 0.289 \\
\hline & Q3 215-254 mg/dL) & $72(19.9)$ & $290(80.1)$ & 0.76 & 0.54 & 1.08 & 0.125 & 0.86 & 0.59 & 1.25 & 0.424 \\
\hline & Q4 (>254 mg/dL) & $66(17.2)$ & $317(82.8)$ & 0.64 & 0.45 & 0.91 & 0.013 & 0.73 & 0.50 & 1.08 & 0.111 \\
\hline \multicolumn{2}{|c|}{$\begin{array}{l}\text { TC linear trend } \\
\text { (every } 20 \mathrm{mg} / \mathrm{dL} \text { increase) }\end{array}$} & $303(20.5)$ & 1176 (79.5) & 0.95 & 0.91 & 0.99 & 0.018 & 0.96 & 0.92 & 1.01 & 0.099 \\
\hline
\end{tabular}

OR: Odds Ratio; CI: Confidence Interval; HDL: high-density lipoprotein; TG: triglycerides; LDL: low-density lipoprotein; TC: total cholesterol; NT was defined as without any neurodevelopmental disorder diagnosis; ADHD was defined as any ADHD diagnosis; the multiple logistic regression model was adjusted for maternal age at delivery, maternal race/ethnicity, maternal education, smoking during pregnancy, intrauterine infection, parity, child's sex, mode of delivery, preterm birth, and birthweight.

For TG, the risk of ADHD diagnosis for the children whose maternal TG levels were $\geq 200 \mathrm{mg} / \mathrm{dL}$ (indicating marginal risk of heart disease) was not statistically significantly different to those children whose mothers had $<200 \mathrm{mg} / \mathrm{dL}$ TG levels (OR $=1.26,95 \% \mathrm{CI}(0.94,1.68)$ ). Compared to mothers with second quartile TG levels, the mothers with first, third or fourth quartile TG levels had a 51\% increased odds of having a child with any ADHD diagnosis $(\mathrm{OR}=1.51,95 \% \mathrm{CI}(1.08,2.10))$, suggesting a "J" shaped association.

When LDL was analyzed as a continuous variable, the average odds of having a child with any ADHD diagnosis dropped 7\% for every $20 \mathrm{mg} / \mathrm{dL}$ increase in maternal LDL levels (OR $=0.93,95 \% \mathrm{CI}$ $(0.87,0.99))$. The MLR results for maternal TC levels did not show any significant association with the child's ADHD diagnosis.

Table 3 shows the associations between maternal HDL levels and the risk of any ADHD diagnosis stratified by the child's sex and the joint effect of maternal HDL levels and the child's sex on ADHD risk. As expected, compared to girls, boys had a three times higher risk of ADHD (OR $=3.25,95 \%$ CI $(2.45,4.30))$. The joint effects of maternal HDL and sex showed that boys whose mothers had $\leq$ median HDL levels had increased odds of having any ADHD diagnosis (OR $=4.25,95 \%$ CI (2.88, 6.26)), compared to girls whose mothers had $>$ median HDL levels. The interaction term between sex and HDL was not statistically significant $(\mathrm{OR}=1.35,95 \% \mathrm{CI}(0.77,2.37))$. Table S3 shows the stratified analysis results for the association between maternal HDL and ADHD. The results indicate that, besides child's sex, smoking during pregnancy, intrauterine infection, parity, mode of delivery, gestational age, and birthweight also influence the association between maternal HDL and ADHD. Higher maternal HDL was more likely associated with a reduced risk of ADHD in the following stratum: boy, never smoker during pregnancy, no intrauterine infection during pregnancy, multiparous, vaginal delivery, full term, and normal birthweight.

Table S4 shows the sensitivity analysis results on the joint effect of maternal HDL and sex by comparing children with specialist ADHD diagnosis and neurotypical children, and the findings were similar. Table S6 shows the results of the sensitivity analyses on the joint effect of maternal HDL and sex by excluding the children whose age of last ADHD diagnosis was under six years, and the findings were also similar. 
Table 3. The joint association of maternal high-density lipoprotein (HDL) levels and child's sex with the risk of ADHD in offspring.

\begin{tabular}{|c|c|c|c|c|c|c|c|}
\hline Sex & Maternal HDL & ADHD, No. (\%) & NT, No. (\%) & Adjusted OR & \multicolumn{2}{|c|}{$95 \% \mathrm{CI}$} & $p$-Value \\
\hline Female & & $85(11.4)$ & $664(88.6)$ & 1.00 & & & \\
\hline Male & & $218(29.9)$ & $512(70.1)$ & 3.25 & 2.45 & 4.30 & $<0.001$ \\
\hline \multicolumn{8}{|c|}{ Joint effects of maternal HDL and sex } \\
\hline \multirow{2}{*}{ Female } & $>$ median & $42(10.5)$ & $359(89.5)$ & 1.00 & & & \\
\hline & $\leq$ median & $43(12.4)$ & 305 (87.6) & 1.14 & 0.72 & 1.81 & 0.564 \\
\hline \multirow{2}{*}{ Male } & >median & $80(24.3)$ & $249(75.7)$ & 2.75 & 1.82 & 4.16 & $<0.001$ \\
\hline & $\leq$ median & $138(34.4)$ & $263(65.6)$ & 4.25 & 2.88 & 6.26 & $<0.001$ \\
\hline
\end{tabular}

NT was defined as without any neurodevelopmental disorder diagnosis; ADHD was defined as any ADHD diagnosis; covariates included maternal age at delivery, maternal race/ethnicity, maternal education, smoking during pregnancy, intrauterine infection, parity, child's sex, mode of delivery, preterm birth, and birthweight.

Table 4 shows the association between maternal TG levels and the risk of any ADHD diagnosis, stratified by the child's sex and the joint effect of maternal TG levels and the child's sex. The joint effects results showed that boys whose mothers had first, third or fourth quartile TG levels had a 394\% increased odds of having any ADHD diagnosis (OR $=4.94,95 \% \mathrm{CI}(2.84,8.58))$, as compared to girls whose mothers had second quartile TG levels. The interaction term between sex and TG was not statistically significant $(\mathrm{OR}=1.03,95 \% \mathrm{CI}(0.51,2.07))$. Table S5 shows the results of the sensitivity analyses on the joint effect of maternal TG and sex by comparing children with specialist ADHD diagnosis and neurotypical children, and the findings were similar. Table S7 shows the results of the sensitivity analyses on the joint effect of maternal TG and sex by excluding the children whose age at the last ADHD diagnosis was under six years, and the findings were also similar. These joint effects across HDL, TG, and sex are further illustrated in Figure 2 using MLR estimation and adjusting for the same covariates. Table S8 shows the results of additional analyses on the association between maternal cholesterol profiles and the risk of other neurodevelopmental disorders other than ADHD, such that maternal HDL and TG levels were not associated with other neurodevelopmental disorders.

Table 4. The joint association of maternal triglycerides (TG) levels and child's sex with the risk of ADHD in offspring.

\begin{tabular}{|c|c|c|c|c|c|c|c|}
\hline Sex & Maternal TG & ADHD, No. (\%) & NT, No. (\%) & Adjusted OR & \multicolumn{2}{|c|}{$95 \%$ CI } & $p$-Value \\
\hline Female & & $85(11.4)$ & $664(88.6)$ & 1.00 & & & \\
\hline Male & & $218(29.9)$ & $512(70.1)$ & 3.31 & 2.50 & 4.39 & $<0.001$ \\
\hline \multicolumn{8}{|c|}{ Joint effects of maternal TG and sex } \\
\hline \multirow{2}{*}{ Female } & Q2 & $16(8.8)$ & $166(91.2)$ & 1.00 & & & \\
\hline & $\mathrm{Q} 1, \mathrm{Q} 3, \mathrm{Q} 4$ & $69(12.2)$ & $498(87.8)$ & 1.48 & 0.83 & 2.65 & 0.184 \\
\hline \multirow{2}{*}{ Male } & Q2 & $42(24.3)$ & $131(75.7)$ & 3.25 & 1.73 & 6.09 & $<0.001$ \\
\hline & Q1, Q3, Q4 & $176(31.6)$ & $381(68.4)$ & 4.94 & 2.84 & 8.58 & $<0.001$ \\
\hline
\end{tabular}

NT was defined as without any neurodevelopmental disorder diagnosis; ADHD was defined as any ADHD diagnosis; covariates included maternal age at delivery, maternal race/ethnicity, maternal education, smoking during pregnancy, intrauterine infection, parity, child's sex, mode of delivery, preterm birth, and birthweight. 


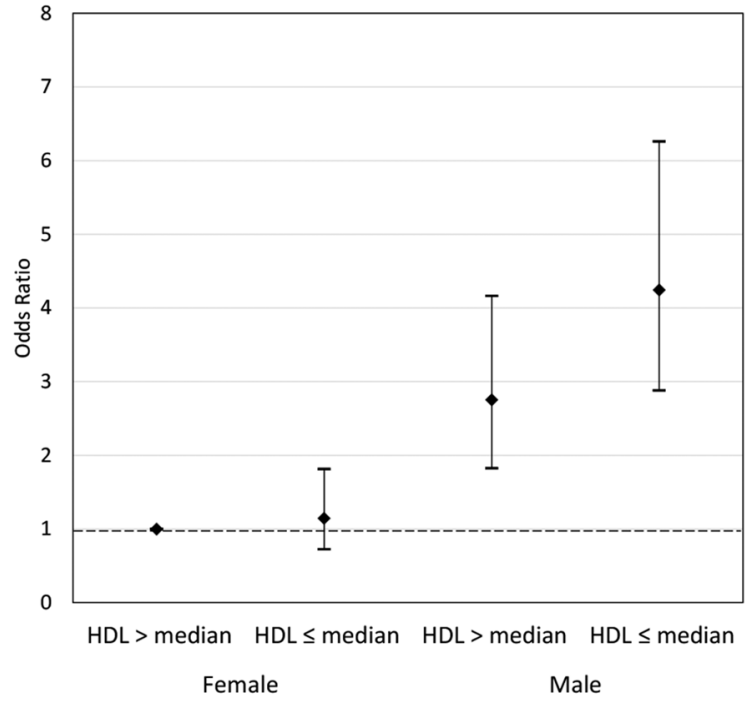

(a)

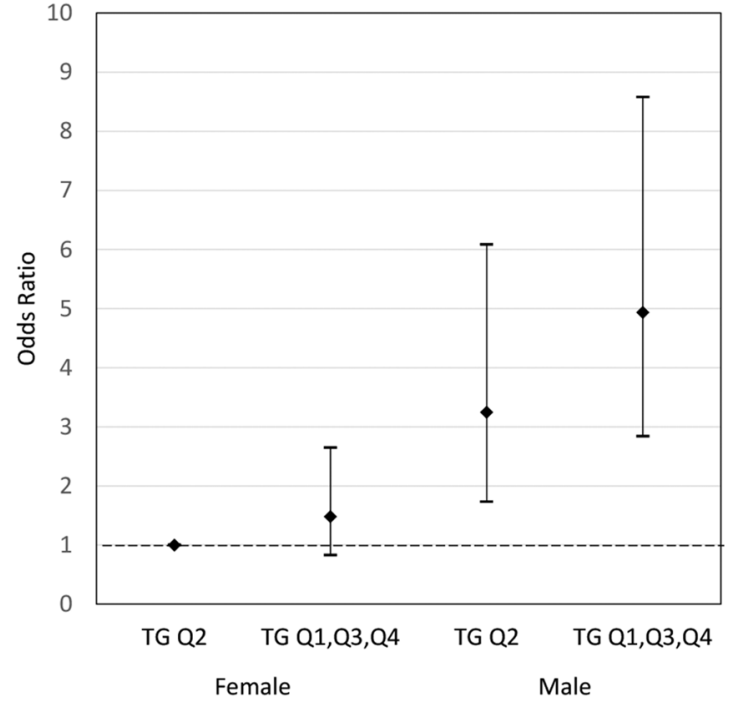

(b)

Figure 2. (a) The odds ratio of any ADHD diagnosis across maternal HDL and child's sex groups using multiple logistic regression estimation; (b) the odds ratio of any ADHD diagnosis across maternal TG and child's sex groups using multiple logistic regression estimation.

\section{Discussion}

Despite the notion that cholesterol is essential for brain health, few prospective birth cohort studies have examined the effect of maternal cholesterol on offspring's neurodevelopment. In the BBC, we found a significant association between maternal cholesterol levels, particularly HDL and TG measured 24-72 h after delivery (a proxy of peripartum maternal cholesterol levels), and ADHD risk in offspring. In contrast, this association is not significant for the risk of other neurodevelopmental disorders. Furthermore, our study sheds new light on the ADHD sex difference by demonstrating that boys are more vulnerable than girls to suboptimal maternal cholesterol levels.

Our study findings were further strengthened by several aspects of our study design. We used clinician diagnosis extracted from the EMRs to define ADHD cases. More than half of the children in the ADHD group had over three ADHD clinician diagnoses in their EMRs. Additionally, over $80 \%$ of ADHD cases in the BBC were diagnosed by a neurodevelopmental specialist, thus, with a much higher specificity and lesser probability of case misclassification. The results of our sensitivity analyses, which restricted ADHD cases to those with a neurobehavioral specialist diagnosis and excluded those with a diagnosis at age younger than six years showed similar effect sizes and levels of significance as for our major findings.

While we cannot make a causality inference, and although biological mechanisms underlying the maternal HDL and child ADHD association remain to be determined, our findings are biologically plausible and in alignment with previous research. The central nervous system (CNS) is insulated from the systemic circulation by the blood brain barrier (BBB). Cholesterol and its carrying lipoproteins in the CNS are mainly synthesized locally within the brain [56,57] while cholesterol carried by plasma lipoproteins cannot move freely across the BBB [37,58]. Most lipoproteins found in the brain are synthesized by glial cells and astrocytes [57]. Additionally, the apolipoprotein B-containing lipoproteins, such as LDL, VLDL, and chylomicron, cannot enter the brain via the BBB [57]. Nevertheless, studies have suggested that plasma-based cholesterol may still affect the integrity and function of neurons and myelin [36,57]. For instance, the discoidal apolipoprotein A-I-containing HDL particles may enter the brain through scavenger receptor class B type I (SR-BI)-mediated uptake and transcytosis [57,59]. Notably, apolipoprotein A-I, which is the major component of plasma HDL, cannot be synthesized in the CNS [60,61]. After entering the CNS, it can further collect 
phospholipids and unesterified cholesterol and undergo maturation into HDL-like lipoproteins in the brain [57]. In addition to small plasma HDL particles, the side-chain oxidized oxysterols, such as 27-hydroxycholesterol, can also cross the BBB [62]. Moreover, peripheral HDL, even without crossing the BBB, may still influence fetal brain development due to its potential protective effect on cerebrovascular endothelial cell function [63]. In sum, the available evidence supports our findings regarding the protective effect of higher maternal HDL levels against ADHD risk in offspring.

The mechanism underlying the actions of maternal TG appears to be different from that underlying HDL. TG cannot cross the BBB but can influence multiple hormonal transportations across the BBB. For example, TG can effectively inhibit leptin transport across the BBB [64]. Besides its beneficial role in reducing obesity risk, leptin is a multifunctional hormone that influences many brain functions including appetite, motivation, learning, memory, and cognition [65].

If further confirmed by future investigation, our findings may have important research, clinical and public health implications. First, our data suggest that pregnant women should maintain a relatively higher level of HDL to meet the need for rapid fetal brain development during pregnancy and to reduce ADHD risk; this is particularly important for male fetuses. Our data indicate that the current clinical cut-off point for HDL ( $>50 \mathrm{mg} / \mathrm{dL}$ ) for nonpregnant women, as recommended by the American Heart Association for reducing the risk of heart disease [54,55], may not be adequate for protecting against ADHD in offspring; thus, a higher cut-off point ( $>60 \mathrm{mg} / \mathrm{dL})$ may be needed for identifying the fetus at risk for future ADHD. Lipid screening is not currently part of prenatal care guidelines, but it is relatively inexpensive and easily measured. Low HDL is modifiable by dietary and lifestyle changes and is treatable with pharmaceuticals.

The long-observed and striking sex difference in ADHD risk continues to be poorly understood. Our study revealed that the maternal HDL and TG effects on ADHD are most pronounced among boys. This sex differences in response to suboptimal nutritional status are also found in other chronic diseases. For example, both human and animal studies showed that male fetuses are more likely to develop hypertension in response to the mother's unfavorable nutrition and metabolism status during pregnancy [66-70]. One potential explanation is that male fetuses are more vulnerable to suboptimal maternal nutrition due to their more rapid in-utero growth compared to females [66-70].

Our study had the following limitations. First, our study only included a single measurement of maternal cholesterol taken 24-72 h after delivery. Ideally, a serial collection of lipid levels throughout pregnancy would best inform our hypotheses. At best, our one-time measurement reflects maternal cholesterol levels during peripartum. Additionally, the change in lipid levels between 24 and $72 \mathrm{~h}$ after delivery might add another potential source of variability for lipid measurement. Second, our study used non-fasting blood samples. The values for TC and TG levels may have been inflated in non-fasting blood samples and thus may have biased our study results towards the null. Further studies using fasting blood samples should be conducted to provide a more precise assessment of optimal TG levels during pregnancy. Third, our study was conducted in a US urban, low-income, primarily minority setting; thus, this was a population at higher risk of exposure to other risk factors for ADHD. Our analyses adjusted for known risk factors of ADHD, but could not adjust for multiple parent-related factors identified in previous studies such as poor parenting [13,14], maltreatment [15], conflict/parent-child hostility [23], and severe early deprivation [24,25]. Although our study sample is not representative of the general US population, research in urban minority populations is limited, and our study findings help to fill in this important data gap. Finally, our adjustment for known risk factors did not include some post-natal factors that could be related to both maternal cholesterol levels and ADHD risk, such as the child's lipid levels. Although it is beyond the scope of this report, a study of the joint effects of cholesterol with other components of metabolic syndrome such as obesity, diabetes, and hypertension, may help to provide greater understanding about the associations between the maternal metabolic constellation and child neurodevelopmental outcomes. A previously published study did show that diabetes could cause a low production of brain cholesterol and its precursors, which in turn could lead to disruptions in synaptic formation and function [71]. Although our study occurred during 
the transition of the American Psychiatric Association's Diagnostic and Statistical Manual (DSM) from the IV to the $\mathrm{V}$ edition, the diagnosis of ADHD in children did not change appreciably [72]. Moreover, the DSM-V lists both ICD-9 and ICD-10 codes for transition purposes [73].

\section{Conclusions}

In this large, prospective, predominantly US urban, low income, minority birth cohort, we found that suboptimal maternal cholesterol levels, in particular low HDL, may increase the risk of ADHD in offspring. The male fetus appears to be particularly vulnerable to suboptimal maternal cholesterol levels. Our findings raise new hypotheses for understanding of origins of ADHD, gender differences and future targets in the prevention of ADHD, and warrant additional investigation.

Supplementary Materials: The following are available online at www.mdpi.com/com/2076-3425/8/1/3/s1. Table S1: ICD-9 and ICD-10 codes for the diagnosis of each neurodevelopmental disorder; Table S2: Maternal and child characteristics for participants excluded and included in the analysis; Table S3: The stratified analysis results on the association between maternal HDL levels (every $20 \mathrm{mg} / \mathrm{dL}$ increase) and the risk of ADHD in offspring; Table S4: The joint association of child's gender and maternal HDL levels with the risk of any specialist ADHD diagnosis; Table S5: The joint association of child's gender and maternal TG levels with the risk of any specialist ADHD diagnosis;Table S6: The joint association of child's gender and maternal HDL levels with the risk of any ADHD diagnosis (last diagnosis at age > than 6 years); Table S7: The joint association of child's gender and maternal TG levels with the risk of any ADHD diagnosis (last diagnosis at age >than 6 years). Table S8: The association between maternal cholesterol and the risk of other neurodevelopmental disorders in offspring.

Acknowledgments: This work is supported by the Health Resources and Services Administration (HRSA) of the US Department of Health and Human Services (HHS) under grant number R40MC27443 and UJ2MC31074. The Boston Birth Cohort (the parent study) is supported in part by the March of Dimes PERI grants (20-FY02-56, \#21-FY07-605); and the National Institutes of Health (NIH) grants (R21ES011666, R01HD041702, R21HD066471, U01AI090727, R21AI079872, and R01HD086013). This information or content and conclusions are those of the authors and should not be construed as the official position or policy of, nor should any endorsements be inferred by HRSA, HHS or the U.S. Government.

Author Contributions: Y.J. conceptualized the study, assumed primary responsibility for laboratory analysis, data cleaning, and statistical analyses, and drafted and revised this manuscript; A.W.R., L.-C.L., H.V., X.H., G.W., H.J., D.P., and M.D.F. provided critical input on the study design, data analyses, interpretation of data and revision of the manuscript; R.A., A.W., and T.S. participated in participant recruitment and follow-up, data collection, and critically reviewed the manuscript; T.R.B. participated in drafting and revising this manuscript; B.Z. oversaw and managed participant recruitment, follow-up, and data collection, and provided critical input on the study design, data analyses, interpretation of data and revision of the manuscript; X.W. is the founder and principal investigator of the Boston Birth Cohort; she oversaw participant recruitment, follow-up and data collection, conceptualized the study and provided critical input on the study design, data analyses, interpretation of data, initial draft, and revision of the manuscript.

Conflicts of Interest: The authors declare no conflict of interest.

\section{References}

1. Pastor, P.N.; Duran, C.; Reuben, C. Quickstats: Percentage of children and adolescents aged 5-17 years with diagnosed attention-deficit/hyperactivity disorder (ADHD), by race and hispanic ethnicity-National health interview survey, united states, 1997-2014. MMWR Morb. Mortal. Wkly. Rep. 2015, 64, 925.

2. Visser, S.N.; Danielson, M.L.; Bitsko, R.H.; Holbrook, J.R.; Kogan, M.D.; Ghandour, R.M.; Perou, R.; Blumberg, S.J. Trends in the parent-report of health care provider-diagnosed and medicated attention-deficit/hyperactivity disorder: United states, 2003-2011. J. Am. Acad. Child Adolesc. Psychiatry 2014, 53, 34-46. [CrossRef] [PubMed]

3. Faraone, S.V.; Sergeant, J.; Gillberg, C.; Biederman, J. The worldwide prevalence of adhd: Is it an american condition? World Psychiatry 2003, 2, 104-113. [PubMed]

4. Barkley, R.A. Attention-Deficit Hyperactivity Disorder: A Handbook for Diagnosis and Treatment; Guilford Publications: New York, NY, USA, 2014.

5. Childress, A.C.; Berry, S.A. Pharmacotherapy of attention-deficit hyperactivity disorder in adolescents. Drugs 2012, 72, 309-325. [CrossRef] [PubMed] 
6. Stergiakouli, E.; Thapar, A. Fitting the pieces together: Current research on the genetic basis of attention-deficit/hyperactivity disorder (adhd). Neuropsychiatr. Dis. Treat. 2010, 6, 551-560. [CrossRef] [PubMed]

7. Getahun, D.; Jacobsen, S.J.; Fassett, M.J.; Chen, W.; Demissie, K.; Rhoads, G.G. Recent trends in childhood attention-deficit/hyperactivity disorder. JAMA Pediatr. 2013, 167, 282-288. [CrossRef] [PubMed]

8. Mannuzza, S.; Klein, R.G. Long-term prognosis in attention-deficit/hyperactivity disorder. Child Adolesc. Psychiatr. Clin. N. Am. 2000, 9, 711-726. [PubMed]

9. Pelham, W.E.; Foster, E.M.; Robb, J.A. The economic impact of attention-deficit/hyperactivity disorder in children and adolescents. J. Pediatr. Psychol. 2007, 32, 711-727. [CrossRef] [PubMed]

10. Schappert, S.M.; Rechtsteiner, E.A. Ambulatory medical care utilization estimates for 2006. Natl. Health Stat. Rep. 2008, 8, 1-29.

11. Biederman, J. Attention-deficit/hyperactivity disorder: A selective overview. Biol. Psychiatry 2005, 57, 1215-1220. [CrossRef] [PubMed]

12. Faraone, S.V.; Perlis, R.H.; Doyle, A.E.; Smoller, J.W.; Goralnick, J.J.; Holmgren, M.A.; Sklar, P. Molecular genetics of attention-deficit/hyperactivity disorder. Biol. Psychiatry 2005, 57, 1313-1323. [CrossRef] [PubMed]

13. Patterson, G.R.; DeGarmo, D.; Forgatch, M.S. Systematic changes in families following prevention trials. J. Abnorm. Child Psychol. 2004, 32, 621-633. [CrossRef] [PubMed]

14. Scott, S.; O'Connor, T.G.; Futh, A.; Matias, C.; Price, J.; Doolan, M. Impact of a parenting program in a high-risk, multi-ethnic community: The pals trial. J. Child Psychol. Psychiatry 2010, 51, 1331-1341. [CrossRef] [PubMed]

15. Jaffee, S.R.; Caspi, A.; Moffitt, T.E.; Polo-Tomas, M.; Price, T.S.; Taylor, A. The limits of child effects: Evidence for genetically mediated child effects on corporal punishment but not on physical maltreatment. Dev. Psychol. 2004, 40, 1047-1058. [CrossRef] [PubMed]

16. Costello, E.J.; Compton, S.N.; Keeler, G.; Angold, A. Relationships between poverty and psychopathology: A natural experiment. JAMA 2003, 290, 2023-2029. [CrossRef] [PubMed]

17. Langley, K.; Rice, F.; van den Bree, M.B.; Thapar, A. Maternal smoking during pregnancy as an environmental risk factor for attention deficit hyperactivity disorder behaviour. A review. Minerva Pediatr. 2005, 57, 359-371. [PubMed]

18. Linnet, K.M.; Dalsgaard, S.; Obel, C.; Wisborg, K.; Henriksen, T.B.; Rodriguez, A.; Kotimaa, A.; Moilanen, I.; Thomsen, P.H.; Olsen, J.; et al. Maternal lifestyle factors in pregnancy risk of attention deficit hyperactivity disorder and associated behaviors: Review of the current evidence. Am. J. Psychiatry 2003, 160, 1028-1040. [CrossRef] [PubMed]

19. Glover, V. Annual research review: Prenatal stress and the origins of psychopathology: An evolutionary perspective. J. Child Psychol. Psychiatry 2011, 52, 356-367. [CrossRef] [PubMed]

20. Grizenko, N.; Shayan, Y.R.; Polotskaia, A.; Ter-Stepanian, M.; Joober, R. Relation of maternal stress during pregnancy to symptom severity and response to treatment in children with ADHD. J. Psychiatry Neurosci. 2008, 33, 10-16. [PubMed]

21. Pheula, G.F.; Rohde, L.A.; Schmitz, M. Are family variables associated with ADHD, inattentive type? A case-control study in schools. Eur. Child Adolesc. Psychiatry 2011, 20, 137-145. [CrossRef] [PubMed]

22. Scahill, L.; Schwab-Stone, M.; Merikangas, K.R.; Leckman, J.F.; Zhang, H.; Kasl, S. Psychosocial and clinical correlates of ADHD in a community sample of school-age children. J. Am. Acad. Child Adolesc. Psychiatry 1999, 38, 976-984. [CrossRef] [PubMed]

23. Lifford, K.J.; Harold, G.T.; Thapar, A. Parent-child relationships and ADHD symptoms: A longitudinal analysis. J. Abnorm. Child Psychol. 2008, 36, 285-296. [CrossRef] [PubMed]

24. O'Connor, T.G.; Rutter, M. Attachment disorder behavior following early severe deprivation: Extension and longitudinal follow-up. English and romanian adoptees study team. J. Am. Acad. Child Adolesc. Psychiatry 2000, 39, 703-712. [CrossRef] [PubMed]

25. Rutter, M.; Beckett, C.; Castle, J.; Colvert, E.; Kreppner, J.; Mehta, M.; Stevens, S.; Sonuga-Barke, E. Effects of profound early institutional deprivation: An overview of findings from a UK longitudinal study of romanian adoptees. Eur. J. Dev. Psychol. 2007, 4, 332-350. [CrossRef]

26. Bhutta, A.T.; Cleves, M.A.; Casey, P.H.; Cradock, M.M.; Anand, K.J. Cognitive and behavioral outcomes of school-aged children who were born preterm: A meta-analysis. JAMA 2002, 288, 728-737. [CrossRef] [PubMed] 
27. Bouchard, M.F.; Bellinger, D.C.; Wright, R.O.; Weisskopf, M.G. Attention-deficit/hyperactivity disorder and urinary metabolites of organophosphate pesticides. Pediatrics 2010, 125, e1270-e1277. [CrossRef] [PubMed]

28. Eubig, P.A.; Aguiar, A.; Schantz, S.L. Lead and PCBs as risk factors for attention deficit/hyperactivity disorder. Environ. Health Perspect. 2010, 118, 1654-1667. [CrossRef] [PubMed]

29. Sagiv, S.K.; Thurston, S.W.; Bellinger, D.C.; Tolbert, P.E.; Altshul, L.M.; Korrick, S.A. Prenatal organochlorine exposure and behaviors associated with attention deficit hyperactivity disorder in school-aged children. Am. J. Epidemiol. 2010, 171, 593-601. [CrossRef] [PubMed]

30. Braun, J.M.; Kahn, R.S.; Froehlich, T.; Auinger, P.; Lanphear, B.P. Exposures to environmental toxicants and attention deficit hyperactivity disorder in u.S. Children. Environ. Health Perspect. 2006, 114, 1904-1909. [PubMed]

31. Froehlich, T.E.; Lanphear, B.P.; Auinger, P.; Hornung, R.; Epstein, J.N.; Braun, J.; Kahn, R.S. Association of tobacco and lead exposures with attention-deficit/hyperactivity disorder. Pediatrics 2009, 124, e1054-e1063. [CrossRef] [PubMed]

32. Nigg, J.T.; Nikolas, M.; Mark Knottnerus, G.; Cavanagh, K.; Friderici, K. Confirmation and extension of association of blood lead with attention-deficit/hyperactivity disorder (ADHD) and ADHD symptom domains at population-typical exposure levels. J. Child Psychol. Psychiatry 2010, 51, 58-65. [CrossRef] [PubMed]

33. Li, M.; Fallin, M.D.; Riley, A.; Landa, R.; Walker, S.O.; Silverstein, M.; Caruso, D.; Pearson, C.; Kiang, S.; Dahm, J.L.; et al. The association of maternal obesity and diabetes with autism and other developmental disabilities. Pediatrics 2016, 137, e20152206. [CrossRef] [PubMed]

34. Rodriguez, A.; Miettunen, J.; Henriksen, T.B.; Olsen, J.; Obel, C.; Taanila, A.; Ebeling, H.; Linnet, K.M.; Moilanen, I.; Jarvelin, M.R. Maternal adiposity prior to pregnancy is associated with adhd symptoms in offspring: Evidence from three prospective pregnancy cohorts. Int. J. Obes. (Lond) 2008, 32, 550-557. [CrossRef] [PubMed]

35. Alberts, B.; Johnson, A.; Lewis, J.; Raff, M.; Roberts, K.; Walter, P. Molecular biology of the cell. In Classic Textbook Now in Its 5th Edition; Garland Science: New York, NY, USA, 2002.

36. Dietschy, J.M.; Turley, S.D. Cholesterol metabolism in the brain. Curr. Opin. Lipidol. 2001, 12, $105-112$. [CrossRef] [PubMed]

37. Dietschy, J.M.; Turley, S.D. Thematic review series: Brain lipids. Cholesterol metabolism in the central nervous system during early development and in the mature animal. J. Lipid Res. 2004, 45, 1375-1397. [CrossRef] [PubMed]

38. Woollett, L.A. Maternal cholesterol in fetal development: Transport of cholesterol from the maternal to the fetal circulation. Am. J. Clin. Nutr. 2005, 82, 1155-1161. [PubMed]

39. Schmid, K.E.; Davidson, W.S.; Myatt, L.; Woollett, L.A. Transport of cholesterol across a bewo cell monolayer: Implications for net transport of sterol from maternal to fetal circulation. J. Lipid Res. 2003, 44, 1909-1918. [CrossRef] [PubMed]

40. Wyne, K.L.; Woollett, L.A. Transport of maternal LDL and HDL to the fetal membranes and placenta of the golden syrian hamster is mediated by receptor-dependent and receptor-independent processes. J. Lipid Res. 1998, 39, 518-530. [PubMed]

41. Hayashi, H. Lipid metabolism and glial lipoproteins in the central nervous system. Biol. Pharm. Bull. 2011, 34, 453-461. [CrossRef] [PubMed]

42. Lippi, G.; Albiero, A.; Montagnana, M.; Salvagno, G.L.; Scevarolli, S.; Franchi, M.; Guidi, G.C. Lipid and lipoprotein profile in physiological pregnancy. Clin. Lab. 2007, 53, 173-177. [PubMed]

43. Scifres, C.M.; Catov, J.M.; Simhan, H.N. The impact of maternal obesity and gestational weight gain on early and mid-pregnancy lipid profiles. Obesity (Silver Spring) 2014, 22, 932-938. [CrossRef] [PubMed]

44. An-Na, C.; Man-Li, Y.; Jeng-Hsiu, H.; Pesus, C.; Shin-Kuo, S.; Heung-Tat, N. Alterations of serum lipid levels and their biological relevances during and after pregnancy. Life Sci. 1995, 56, 2367-2375. [CrossRef]

45. Van Exel, E.; de Craen, A.J.; Gussekloo, J.; Houx, P.; Bootsma-van der Wiel, A.; Macfarlane, P.W.; Blauw, G.J.; Westendorp, R.G. Association between high-density lipoprotein and cognitive impairment in the oldest old. Ann. Neurol. 2002, 51, 716-721. [CrossRef] [PubMed]

46. Muckle, T.J.; Roy, J.R. High-density lipoprotein cholesterol in differential diagnosis of senile dementia. Lancet 1985, 1, 1191-1193. [CrossRef] 
47. Merched, A.; Xia, Y.; Visvikis, S.; Serot, J.; Siest, G. Decreased high-density lipoprotein cholesterol and serum apolipoprotein AI concentrations are highly correlated with the severity of Alzheimer's disease. Neurobiol. Aging 2000, 21, 27-30. [CrossRef]

48. Wang, G.; Divall, S.; Radovick, S.; Paige, D.; Ning, Y.; Chen, Z.; Ji, Y.; Hong, X.; Walker, S.O.; Caruso, D.; et al. Preterm birth and random plasma insulin levels at birth and in early childhood. JAMA 2014, 311, 587-596. [CrossRef] [PubMed]

49. Wang, X.; Zuckerman, B.; Pearson, C.; Kaufman, G.; Chen, C.; Wang, G.; Niu, T.; Wise, P.H.; Bauchner, H.; $\mathrm{Xu}, \mathrm{X}$. Maternal cigarette smoking, metabolic gene polymorphism, and infant birth weight. JAMA 2002, 287, 195-202. [CrossRef] [PubMed]

50. Kumar, R.; Tsai, H.J.; Hong, X.; Liu, X.; Wang, G.; Pearson, C.; Ortiz, K.; Fu, M.; Pongracic, J.A.; Bauchner, H.; et al. Race, ancestry, and development of food-allergen sensitization in early childhood. Pediatrics 2011, 128, e821-e829. [CrossRef] [PubMed]

51. Zhang, S.; Liu, X.; Necheles, J.; Tsai, H.-J.; Wang, G.; Wang, B.; Xing, H.; Li, Z.; Liu, X.; Zang, T. Genetic and environmental influences on serum lipid tracking: A population-based, longitudinal Chinese twin study. Pediatr. Res. 2010, 68, 316-322. [CrossRef] [PubMed]

52. Raghavan, R.; Riley, A.W.; Volk, H.; Caruso, D.; Hironaka, L.; Sices, L.; Hong, X.; Wang, G.; Ji, Y.; Brucato, M. Maternal multivitamin intake, plasma folate and vitamin B12 levels and autism spectrum disorder risk in offspring. Paediatr. Perinat. Epidemiol. 2017. [CrossRef] [PubMed]

53. Brucato, M.; Ladd-Acosta, C.; Li, M.; Caruso, D.; Hong, X.; Kaczaniuk, J.; Stuart, E.A.; Fallin, M.D.; Wang, X. Prenatal exposure to fever is associated with autism spectrum disorder in the boston birth cohort. Autism Res. 2017, 10, 1878-1890. [CrossRef] [PubMed]

54. Miller, M.; Stone, N.J.; Ballantyne, C.; Bittner, V.; Criqui, M.H.; Ginsberg, H.N.; Goldberg, A.C.; Howard, W.J.; Jacobson, M.S.; Kris-Etherton, P.M.; et al. Triglycerides and cardiovascular disease: A scientific statement from the American heart association. Circulation 2011, 123, 2292-2333. [CrossRef] [PubMed]

55. Program, N.C.E. Expert panel on detection, evaluation, and treatment of high blood cholesterol in adults (adult treatment panel iii): Third report of the national cholesterol education program (NCEP) expert panel on detection, evaluation, and treatment of high blood cholesterol in adults (adult treatment panel iii) final report. Circulation 2002, 106, 3143-3421.

56. Bjorkhem, I.; Meaney, S. Brain cholesterol: Long secret life behind a barrier. Arterioscler. Thromb. Vasc. Biol. 2004, 24, 806-815. [CrossRef] [PubMed]

57. Vitali, C.; Wellington, C.L.; Calabresi, L. HDL and cholesterol handling in the brain. Cardiovasc. Res. 2014, 103, 405-413. [CrossRef] [PubMed]

58. Zlokovic, B.V. The blood-brain barrier in health and chronic neurodegenerative disorders. Neuron 2008, 57, 178-201. [CrossRef] [PubMed]

59. Balazs, Z.; Panzenboeck, U.; Hammer, A.; Sovic, A.; Quehenberger, O.; Malle, E.; Sattler, W. Uptake and transport of high-density lipoprotein (HDL) and HDL-associated alpha-tocopherol by an in vitro blood-brain barrier model. J. Neurochem. 2004, 89, 939-950. [CrossRef] [PubMed]

60. Koch, S.; Donarski, N.; Goetze, K.; Kreckel, M.; Stuerenburg, H.J.; Buhmann, C.; Beisiegel, U. Characterization of four lipoprotein classes in human cerebrospinal fluid. J. Lipid Res. 2001, 42, 1143-1151. [PubMed]

61. Demeester, N.; Castro, G.; Desrumaux, C.; de Geitere, C.; Fruchart, J.C.; Santens, P.; Mulleners, E.; Engelborghs, S.; de Deyn, P.P.; Vandekerckhove, J.; et al. Characterization and functional studies of lipoproteins, lipid transfer proteins, and lecithin: Cholesterol acyltransferase in CSF of normal individuals and patients with Alzheimer's disease. J. Lipid Res. 2000, 41, 963-974. [PubMed]

62. Björkhem, I. Crossing the barrier: Oxysterols as cholesterol transporters and metabolic modulators in the brain. J. Intern. Med. 2006, 260, 493-508. [CrossRef] [PubMed]

63. Calabresi, L.; Gomaraschi, M.; Franceschini, G. Endothelial protection by high-density lipoproteins: From bench to bedside. Arterioscler. Thromb. Vasc. Biol. 2003, 23, 1724-1731. [CrossRef] [PubMed]

64. Banks, W.A.; Coon, A.B.; Robinson, S.M.; Moinuddin, A.; Shultz, J.M.; Nakaoke, R.; Morley, J.E. Triglycerides induce leptin resistance at the blood-brain barrier. Diabetes 2004, 53, 1253-1260. [CrossRef] [PubMed]

65. Morrison, C.D. Leptin signaling in brain: A link between nutrition and cognition? Biochim. Biophys. Acta 2009, 1792, 401-408. [CrossRef] [PubMed]

66. Eriksson, J.G.; Kajantie, E.; Osmond, C.; Thornburg, K.; Barker, D.J. Boys live dangerously in the womb. Am. J. Hum. Biol. 2010, 22, 330-335. [CrossRef] [PubMed] 
67. Ravelli, A.C.; van Der Meulen, J.H.; Osmond, C.; Barker, D.J.; Bleker, O.P. Obesity at the age of 50 y in men and women exposed to famine prenatally. Am. J. Clin. Nutr. 1999, 70, 811-816. [PubMed]

68. Grigore, D.; Ojeda, N.B.; Alexander, B.T. Sex differences in the fetal programming of hypertension. Gend. Med. 2008, 5 (Suppl. A), S121-S132. [CrossRef] [PubMed]

69. Ozaki, T.; Nishina, H.; Hanson, M.A.; Poston, L. Dietary restriction in pregnant rats causes gender-related hypertension and vascular dysfunction in offspring. J. Physiol. 2001, 530, 141-152. [CrossRef] [PubMed]

70. Woods, L.L.; Ingelfinger, J.R.; Rasch, R. Modest maternal protein restriction fails to program adult hypertension in female rats. Am. J. Physiol. Regul. Integr. Comp. Physiol. 2005, 289, R1131-R1136. [CrossRef] [PubMed]

71. Suzuki, R.; Lee, K.; Jing, E.; Biddinger, S.B.; McDonald, J.G.; Montine, T.J.; Craft, S.; Kahn, C.R. Diabetes and insulin in regulation of brain cholesterol metabolism. Cell Metab. 2010, 12, 567-579. [CrossRef] [PubMed]

72. American Psychiatric Association. Using DSM-5 in the Transition to ICD-10. Available online: https: / / www.psychiatry.org/psychiatrists/practice/dsm/icd-10 (accessed on 22 October 2017).

73. American Psychiatric Association. Diagnostic and Statistical Manual of Mental Disorders (dsm-5®); American Psychiatric Pub.: Washington, DC, USA, 2013.

(C) 2017 by the authors. Licensee MDPI, Basel, Switzerland. This article is an open access article distributed under the terms and conditions of the Creative Commons Attribution (CC BY) license (http:/ / creativecommons.org/licenses/by/4.0/). 